\title{
Technical support and delegation to practice staff - status quo and (possible) future perspectives for primary health care in Germany
}

\author{
Elisabeth Urban", Dominik Ose, Stefanie Joos, Joachim Szecsenyi and Antje Miksch
}

\begin{abstract}
Background: Primary health care in industrialized countries faces major challenges due to demographic changes, an increasing prevalence of chronic diseases and a shortage of primary care physicians. One approach to counteract these developments might be to reduce primary care physicians' workload supported by the use of health information technology (HIT) and non-physician practice staff. In 2009, the U.S. Commonwealth Fund (CWF) conducted an international survey of primary care physicians which the present secondary descriptive analysis is based on. The aim of this analysis was twofold: First, to explore to what extend German primary care physicians already get support by HIT and non-physician practice staff, and second, to show possible future perspectives.
\end{abstract}

Methods: The CWF questionnaire was sent to a representative random sample of 1,500 primary care physicians all over Germany. The data was descriptively analyzed. Group comparisons regarding differences in gender and age groups were made by means of Chi Square Tests for categorical variables. An alpha-level of $p<0.05$ was used for statistical significance.

Results: Altogether 715 primary care physicians answered the questionnaire (response rate 49\%). Seventy percent of the physicians use electronic medical records. Technical features such as electronic ordering and access to laboratory parameters are mainly used. However, the majority does not routinely use technical functions for drug prescribing, reminder-systems for guideline-based interventions or recall of patients. Six percent of surveyed physicians are able to transfer prescriptions electronically to a pharmacy, $1 \%$ use email communication with patients regularly. Seventy-two percent of primary care physicians get support by non-physician practice staff in patient care, mostly in administrative tasks or routine preventive services. One fourth of physicians is supported in telephone calls to the patient or in patient education and counseling.

Conclusion: Within this sample the majority of primary care physicians get support by HIT and non-physician practice staff in their daily work. However, the potential has not yet been fully used. Supportive technical functions like electronic alarm functions for medication or electronic prescribing should be improved technically and more adapted to physicians' needs. To warrant pro-active health care, recall and reminder systems should get refined to encourage their use. Adequately qualified non-physician practice staff could play a more active role in patient care. Reimbursement should not only be linked to doctors', but also to non-physician practice staff services.

Keywords: Primary care, Health information technology, Non-physician practice staff, Support, Delegation, Electronic prescribing, Electronic communication, Recall system, Reminder system

\footnotetext{
* Correspondence: elisabeth.urban@med.uni-heidelberg.de

Department of General Practice and Health Services Research, University of Heidelberg Hospital, Heidelberg, Germany
} 


\section{Background}

Strengthening the primary care setting is an important goal within the German health care system. Primary care contributes to a more equal distribution of health care services within populations and can result in lower health care costs [1]. Internationally, there are great efforts to strengthen primary care and adapt it to recent health care requirements [2]. As in other countries, primary health care in Germany faces major challenges: The demographic development with a growing percentage of older people as well as the increasing prevalence of chronic diseases and multimorbidity contributes to an increasing demand for health care services. Nearly ninety percent of German primary care physicians see patients with multiple chronic diseases frequently [3]. On the other side, Germany like other western countries is confronted with a shortage in primary care physicians, especially in rural areas [4].

In 2009, the U.S. Commonwealth Fund (CWF) conducted a survey of primary care physicians in 11 countries. The survey revealed considerable discrepancies of the primary care physicians' perspective in the different health care systems. Results of the survey in international comparison have already been published: In Germany, the proportion of doctors who are dissatisfied with their job and health care system is significantly higher than in other countries. Most of the respondents in Germany express the need for fundamental changes or even complete reforms of the health care system. For the majority of primary care physicians the time required for accounting, documentation of clinical information or for legal requirements or coordination of patient care is very problematic $[5,6]$. These findings confirm the results from previously conducted CWF-surveys in Germany [3].

In the context of growing health care requirements and a shortage of physicians in primary care, these findings paint a rather gloomy picture of the future of German primary health care. To counteract this development, concepts must be evolved to secure nationwide primary health care in the long term.

Health information technology (HIT) and electronic medical records (EMR) have the potential to support physicians by reducing administrative and organizational tasks. Furthermore, EMR offer the possibility to integrate electronic reminders or alerts. HIT might even have an effect on patient safety [7]. The implementation of an EMR in primary care can lead to reduced costs for example in drug expenditure [8]. Routine electronic communication with patients via email or telephone represents a new approach in patient care.

Additionally, primary care physicians can be supported by non-physician practice staff in medical tasks. In other countries, delegation of medical tasks or even substitution of doctors by non-physician practice staff is already more established than in Germany [9]. The shift from acute towards chronic diseases demands a change in health care management. Concepts like the chronic care model emphasize the provision of pro-active care by practice teams composed of doctors and non-physician practice staff [10-12].

The aim of the present secondary analysis of the CWF-data is twofold. The first aim is to explore to what extent German primary care physicians get support in daily routine by HIT or non-physician practice staff. The second aim is to identify possible actions for improvement and future perspectives to reduce the physicians' workload.

\section{Methods}

The Commonwealth Fund (CWF) regularly conducts international surveys of patients' and physicians' care experiences and ratings on dimensions of care. In 2009, 11 countries took part in a survey of primary care physicians: Australia, Canada, France, Germany, Italy, the Netherlands, New Zealand, Norway, Sweden, the United Kingdom, and the United States of America. The survey was carried out from February to July and was coordinated by Harris Interactive Inc. In all countries, either structured interviews by telephone were conducted or questionnaires were provided by mail or online. The original questionnaire was translated into the language of each country. Altogether, 10,320 interviews were conducted among primary care physicians.

In Germany, the survey was financed by the Institute for Quality and Efficiency in Health Care (Institut für Qualität und Wirtschaftlichkeit im Gesundheitswesen, IQWiG) and conduced and coordinated by the Department of General Practice and Health Services Research at the University Hospital Heidelberg. For this survey a representative sample of 1,500 primary care physicians in Germany was randomly chosen. The distribution of physicians within all Federal States of Germany was adapted from data of the National Association of Statutory Health Insurance Physicians (Kassenärztliche Bundesvereinigung, KBV). The participants of the study in Germany were general practitioners as well as specialists for internal medicine and for pediatrics working in primary care. As an incentive, all participating physicians received 20 Euros which could optionally be donated to the organization Médecins Sans Frontières. To increase the response rate, two reminders were sent out during the following six weeks after the first contact. Nonresponders were asked to return at least a postcard with sociodemographic data and a general judgment about the German health care system. Details of the data acquisition have already been published [5].

All data in this study were categorical variables and were therefore analyzed as frequencies and percentages. Results were displayed descriptively. All statistical 
analyses were conducted with SPSS version 18.0 (SPSS Inc., Chicago IL, USA). Group comparisons regarding differences in gender and age groups (up to the age of 49 years and age of 50 years and over) were made by means of Chi Square Tests for categorical variables. An alpha-level of $\mathrm{p}<0.05$ was considered statistically significant. However, as this was an exploratory analysis, p-values can only be descriptive in nature and therefore should be interpreted carefully. Deriving causal links from these findings should be made with caution.

\section{Results}

In Germany, out of a sample of 1,500 primary care physicians, 715 physicians answered the questionnaire (response rate $49 \%$ ). This response rate was above average in comparison to all other countries [5]. Forty-nine letters were returned because of invalid post addresses. Moreover 123 physicians (9\%) did not answer the questionnaire, but sent back the non-responder postcard.

\section{Respondents}

Regarding to gender, federal state and medical specialization, the sample differed only minimally compared to data from the KBV, that means a deviation not exceeding 3\% per category. A comparison of the sample with non-responders revealed no significant differences regarding age, gender, location of practice, working experience of physicians, working in a multidisciplinary team, or overall satisfaction with the health care system [6].

Tables 1 and 2 show the demographic data of all surveyed primary care physicians and practices.

As a result $497(70 \%)$ primary care physicians in this survey use EMR. Routinely, 450 (63\%) order laboratory tests electronically and 557 (78\%) have electronic access to the laboratory results. Moreover 398 (56\%) physicians routinely use electronic documentation of results and diseases, 233 (33\%) do not at all. Electronic alarm functions for drug dosage or drug interaction were routinely used by 177 (25\%) physicians, occasionally by 125 (18\%) and not at all by 407 (57\%). Furthermore 428 (60\%) physicians were able to prescribe drugs with the use of a computer, but in contrast only $42(6 \%)$ have the possibility to transfer prescriptions to a pharmacy electronically. Figure 1 shows the use of certain electronic features and technologies.

The currently used medical record system of surveyed practices enables 587 (82\%) primary care physicians without major effort to generate a list of patients with a specified diagnosis, 320 (45\%) can list their patients dependent on laboratory results. To extract a list of the current medication of patients is easy or somewhat difficult for 498 (70\%) physicians, correlating to 481 (67\%) who routinely provide a written list of medication to the
Table 1 Physicians characteristics $\left(n=715^{*}\right)$

\begin{tabular}{llrr}
\hline & & $\mathbf{n}$ & $\%$ \\
\hline Age & $<35$ & 4 & 1 \\
\hline & $35-49$ & 276 & 39 \\
\hline Gender & $50-64$ & 384 & 54 \\
\hline & $>64$ & 49 & 7 \\
\hline Working time per week & Male & 455 & 64 \\
\hline & Female & 252 & 35 \\
\hline & up to 30 & 58 & 8 \\
\hline & 31 to 40 & 105 & 15 \\
\hline 41 to 50 & 232 & 32 \\
\hline Working experience in PC & 51 to 60 & 220 & 31 \\
\hline (years) & 61 to 70 & 54 & 7 \\
\hline & 71 to 99 & 36 & 5 \\
\hline$<5$ & 83 & 12 \\
\hline Specialisation & 5 to 10 & 123 & 17 \\
\hline & 11 to 20 & 240 & 34 \\
\hline & $>20$ & 251 & 35 \\
\hline & GP/ Int.Med. & 646 & 90 \\
\hline & Pediatrician & 69 & 10 \\
\hline
\end{tabular}

${ }^{*} \mathrm{n}$ varies due to missing values.

patient. Additionally 431 (60\%) of the physicians are able without major effort to generate a list of patients for whom tests or preventive care are due, but only 124 (17\%) do routinely use a computerized recall system for patients with preventive or follow-up care needs (for

Table 2 Practice characteristics $\left(n=715^{*}\right)$

\begin{tabular}{llrr}
\hline & & $\mathbf{n}$ & \% \\
\hline Number of physicians & 1 & 373 & 52 \\
\hline & 3 to 5 & 229 & 32 \\
\hline Number of non-physicians & 6 to 8 & 95 & 13 \\
\hline & 0 & 21 & 1 \\
\hline 1 to 3 & 436 & 31 \\
\hline & 4 to 6 & 196 & 27 \\
\hline & 7 to 10 & 49 & 7 \\
\hline Location of practice & $>10$ & 7 & 1 \\
\hline & City & 159 & 22 \\
\hline & Suburb & 73 & 10 \\
\hline Small town & 272 & 38 \\
\hline Number of patients / week & Rural area & 193 & 27 \\
\hline & up to 200 & 326 & 46 \\
\hline & 201 to 400 & 314 & 44 \\
\hline & 401 to 600 & 51 & 7 \\
\hline Practice part of network & 601 to 900 & 5 & 1 \\
\hline & yes & 125 & 18 \\
\hline & no & 584 & 82 \\
\hline
\end{tabular}

${ }^{*} \mathrm{n}$ varies due to missing values. 


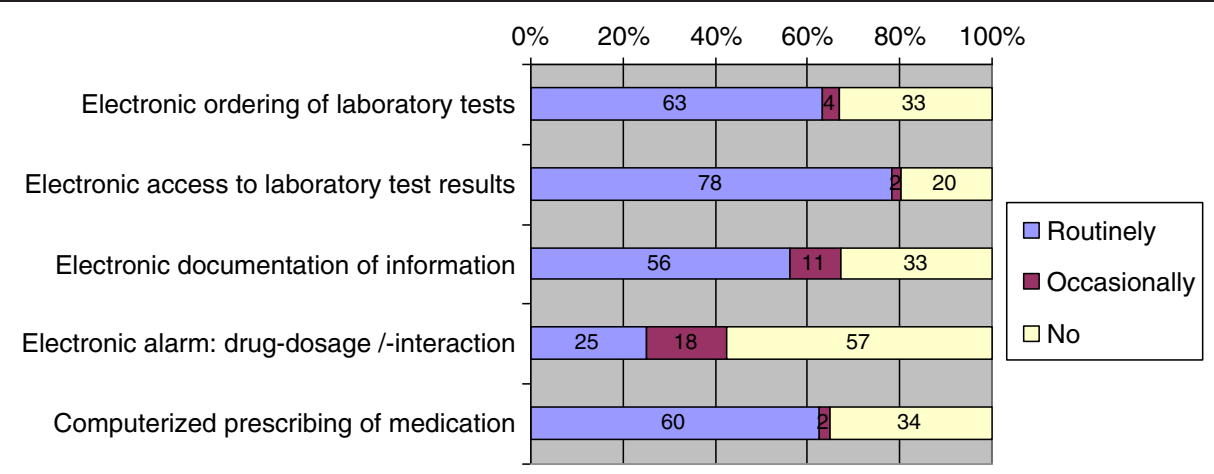

Figure 1 Use of certain electronic features and technologies by physicians.

example vaccinations or $\mathrm{HbA} 1 \mathrm{c}$ testing in patients with diabetes). Similarly, only 85 (12\%) physicians get computer-based reminders of guideline-based interventions or screening tests. Whereas 454 (64\%) and 545 (76\%) physicians do not use recall or reminders in patient care, respectively.

Only 10 (1\%) physicians use email communication with patients for clinical or administrative purposes regularly, 424 (59\%) never; even though 319 (45\%) physicians estimate, that $1-9 \%$ of direct patient visitations of the last week could have been handled by phone or email contact with the patient. Out of the sample 51 (7\%) physicians claim to get extra payment for nonpersonal interaction with patients, whereas $584(82 \%)$ declare to get no additional fee.

When comparing gender and age groups in this survey, some differences could be seen. Male physicians were significantly more likely to use HIT $(80 \%)$ compared to female physicians (64\%). Furthermore, younger physicians (up to the age of 49 years) were significantly more likely to use electronic features like access to laboratory results or electronic documentation as well as regular email with patients.

Altogether $516(72 \%)$ primary care physicians declare that within their practice teams non-physician practice staff takes responsibility in patient care, 427 (60\%) physicians claim to get support by non-physician practice staff in administrative services as ordering tests, writing prescriptions for long-term medication or in delivering routine preventive services. Furthermore 179 (25\%) physicians report that their non-physician practice staff routinely calls patients to check on medications, symptoms and to help coordinate care inbetween visits, 179 (25\%) and 156 (22\%) physicians, respectively, are supported by non-physician practice staff in patient education on self-management or counseling on prevention. Figure 2 gives an overview of tasks non-physician practice staff carries out in patient care. Additionally 112 (16\%) physicians declare to get extra payment for specialization of non-physician practice staff, 554 (78\%) claim they get no extra payment.

Regarding gender and age of primary care physicians, there were no significant differences in delegation of tasks to non-physician practice staff.

\section{Discussion}

\section{Technical support of primary care physicians}

Our results show that the majority of primary care physicians work with EMR in daily routine. Electronic

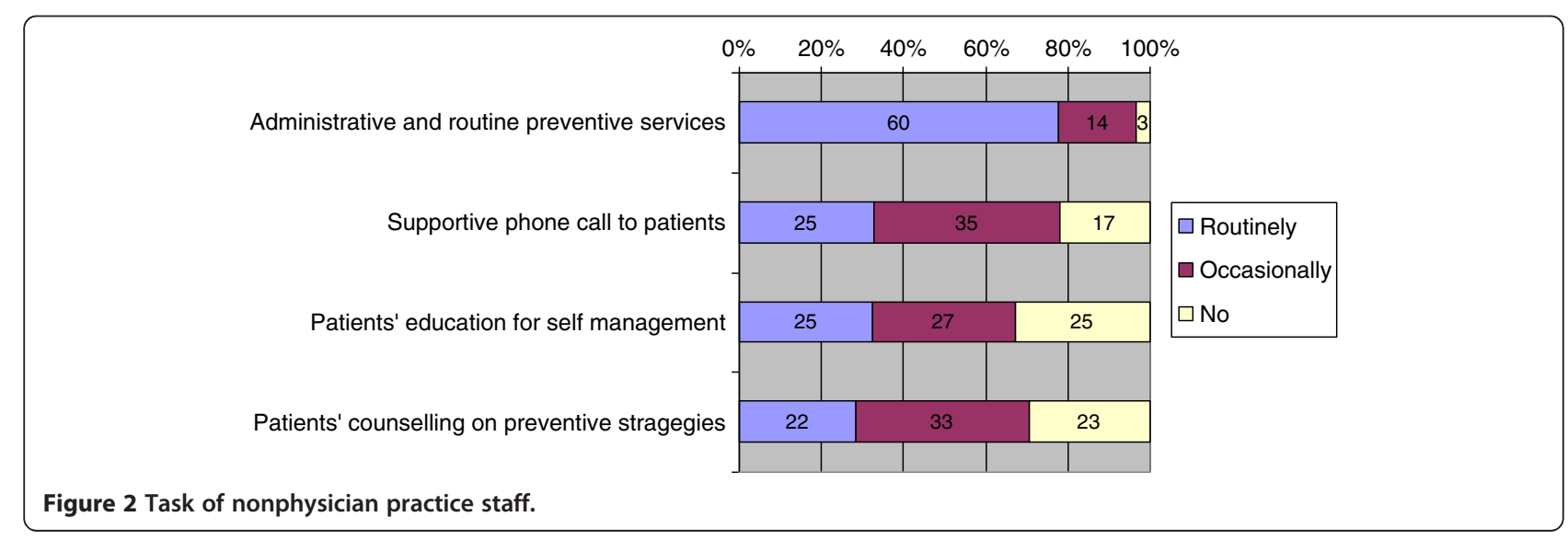


features are mostly used to provide facilitation of administrative and routine work tasks such as electronic ordering and access to laboratory tests or electronic documentation of clinical information. Adequate HIT has the potential to improve practice management and quality of care $[13,14]$. Studies show advantages of paperless medical records [15], but also negative aspects of EMR as structural changes of the physician-patientencounter for example by the position of the computer as well as reduced eye-to-eye contact and an increased duration of the visit are known [16,17].

The potential benefit of using electronic alarm functions for drug dosage or drug interaction is not fully utilized by physicians in this survey. There is evidence that computerized advice on drug dosage can improve the prescribing mode of medication. Often physicians complain about unnecessary or insufficient electronic alerts, this may be a reason for the low utilization of these functions. More research on design and context as well as how the advice should be delivered is needed to meet physicians' needs $[18,19]$.

While nearly two thirds of all surveyed primary care physicians are able to prescribe drugs computerized, only a minority is able to transfer prescriptions to a pharmacy electronically. In other countries, electronic prescribing, including electronic transfer of the prescription from the practice to a pharmacy, is enhanced through incentives by politics [20]. There is evidence that electronic prescribing of drugs can increase effective delivering of health care and patient safety by reducing medical errors in medication and can safe costs [21-23]. Studies show barriers towards electronic prescribing including interruption in work processes and security concerns. Therefore, practice and pharmacy transformation and redesign of work processes are required [24,25].

Only few physicians do routinely recall patients for preventive or follow-up care, although anticipatory and pro-active concepts in health care are essential [10-12]. Analogously, only a minority of physicians use computer-based reminders of guideline-based intervention or screening tests in daily routine. There is evidence that EMR reminders have an effect on provider behaviour regarding guideline or process adherence [26] and can improve medical outcome parameters [27]. Studies show that physicians appreciate electronic reminders for specific tasks if these alerts are accurate and do not disturb workflow [28]. In this analysis, a possible cause for the low utilization of recall or reminder in patient care may be a different understanding of these terms by physicians. In Germany, disease management programs for chronic diseases as diabetes or asthma are nationwide implemented since 2003. Recall of patients, for example for routine consultations or due examinations represents a core content of these programs. As the majority of physicians are nowadays enrolled in these programs, a higher rate of recalls should be assumed in reality for German primary care. Nevertheless, to guarantee adaption to users' needs and to improve pro-active health care concepts, further research on current use, improvement and implementation of recall and reminder systems in primary health care in Germany is needed.

Yet another way to improve pro-active health care would be to support self-management of chronically ill patients by improving the utilization of ehealth, for example telemedical devices. In Germany, so far ehealthsystems are not routinely implemented nationwide. Studies exist, which show that patients in Germany do not know well about telemedical devices, but the majority approves the idea to use them in case of illness. Elderly approve less of ehealth, especially fearing the loss of personal contact with their physician [29]. How these issues have to be met, should be the content of further research.

Electronic communication via email with patients for clinical or administrative purposes is barely used by all surveyed physicians, even though they claim potential for this additional communication technology. Studies in other countries show that physicians and patients are willing to use this communication form for discussing different topics such as mostly non-acute medical symptoms, information about test results or administrative issues [30]. Physicians and patients claim advantages like saving time; concerns are expressed regarding security and confidentiality of emails. Some surveyed physicians declared they got extra financial compensation for nonpersonal communication via email or telephone between doctors and patients. Indeed, patients with a private health insurance can be billed for counseling by phone. Even in some cases of patients with a statutory health insurance, which cover $90 \%$ of German population, physicians can receive financial compensation for nonpersonal communication. But in general, no specific reimbursement or incentive for email communication between physicians and patients in Germany exists. Non-personal communication between non-physician practice staff and patients can not be billed at all. By introducing adequate financial compensation, the use of new communication technologies in patient care could be facilitated.

The significantly enhanced use of HIT and email with patients by younger and male primary care physicians could be explained by more common use of information technologies in younger generations and a greater affinity of men to use technical functions. It can be expected, that future generations of physicians as well as patients will have an increased demand for HIT and nonpersonal communication forms. 


\section{Support of primary care physicians by practice staff}

Over two thirds of primary care physicians get support in their daily work by sharing responsibility in patient care with non-physician practice staff. Whereas nonphysician practice staff supports in administrative work and the delivery of routine preventive services, a more active role of non-physician practice staff in Germany is not common. Within other countries like Sweden or the United Kingdom, non-physician clinicians take responsibilities in patient care more often [5]. There is evidence that appropriately trained non-physician practice staff can ensure high quality in patient care and patient education [31-34]. In Germany, most primary care practices employ doctors' assistants; only $6 \%$ of all practices employ a nurse [35], who are trained differently. Doctors' assistants in Germany require additional education for taking more responsibility in patient care especially in aspects of medical care. An implementation of such education programmes has now been started [36,37]. Furthermore, the legal framework in Germany now allows physicians to delegate medical tasks like home visits, certain diagnostic examinations or special consultation hours for chronically ill patients to qualified non-physician practice staff. However, there is still a controversial discussion between stakeholders, politics and physicians in Germany about suitable tasks to delegate to non-physician practice staff [38]. It is important to consider the physicians' perspective for future developments.

\section{Strengths}

A strength of the study is the representative, randomly chosen sample of primary care physicians of all federal states of Germany. Therefore, the results can be interpreted as representative for Germany. The response rate of $49 \%$ was above average compared to the other surveyed countries and meets international standards in primary care $[39,40]$. No sociodemographic differences were identified between participants and nonresponders.

\section{Limitations}

In general, a questionnaire may be understood differently by surveyed persons. The computerized generation of certain lists of patient' information was categorized into 'easy', 'somewhat difficult' and 'difficult' by the survey. Inter-personal rating differences should be considered when interpreting the results. Some questions could have been understood differently by the physicians. For example, the question "Do you use any of the following technologies in your practice: Electronic prescribing of medication?" does not explicitly elucidate whether a common way of computerized prescribing is used (computer-based generation of the prescription form, electronic fill-in by the physician, printing, validation by manual signature of the physician) or a fully electronic way of prescribing with electronic signature of the prescription and electronic transfer to the pharmacy which is not routinely used in Germany so far.

\section{Conclusion}

German primary care physicians already get support in daily working routine by HIT and non-physician practice staff. However, the potential is not yet fully used. To increase the adoption of technical features like electronic alarm functions for medication or electronic prescribing, these should be technically improved and more adapted to physicians' needs. Also, recall and reminder systems could be further developed to enable a more pro-active health care planning. New ways of communication via email could represent new forms of non-personal encounters of physicians and patients. Non-physician practice staff could play a more active role in health care. Patient education or counseling as well as routine telephone calls or home visits could be possible new working fields for doctors' assistants in Germany. Therefore, adequate qualification of non-physician practice staff is mandatory and needs further development. Reimbursement should not only be linked to doctors', but also to non-physician practice staff services. Primary care physicians should be more supported in daily routine to improve job satisfaction and to counteract the shortage of primary care physicians in the long-term.

\section{Competing interests}

The authors declare that they have no competing interests.

\section{Authors' contribution}

AM, SJ and JSz conducted the German part of the CWF-survey in 2009. EU analyzed with AM and DO the data of the survey and wrote this publication. All authors made contribution to the manuscript and approved the final publication.

\section{Acknowledgements}

The German part of the CWF-survey in 2009 was financed and supported by the Institute for Quality and Efficiency in Health Care (Institut für Qualität und Wirtschaftlichkeit im Gesundheitswesen, IQWiG).

Received: 28 February 2012 Accepted: 23 June 2012

Published: 1 August 2012

\section{References}

1. Starfield B, Shi L, Macinko J: Contribution of Primary Care to Health Systems and Health. Milbank Q 2005, 83(Suppl 3):457-502.

2. Bodenheimer T, Pham HH: Primary Care: Current problems and proposed solutions. Health Aff 2010, 29(Suppl 5):799-805.

3. Koch K, Gehrmann U: Sawicki PT: Primary Care in Germany - an International Comparison. Results of a Survey Using a Validated Instrument. Dtsch Arztebl 2007, 104(Suppl 38):A2584-A2591.

4. Steinhaeuser J, Joos S, Szecsenyi J, Miksch A: A comparison of the workload of rural and urban primary care physicians in Germany: analysis of a questionnaire survey. BMC Fam Pract 2011, 12:112.

5. Schoen C, Osborn R, Doty MM, Squires D, Peugh J, Applebaum S: A survey of primary care physicians in eleven countries, 2009: perspectives on care, costs, and experiences. Health Aff 2009, 28(Suppl 6):1171-1183. 
6. Koch K, Miksch A, Schürmann C, Joos S, Sawicki PT: The German health care system in international comparison: the primary care physicians' perspective. Dtsch Arztebl Int 2010, 108(Suppl 15):255-261.

7. Parente ST, McCullough JS: Health Information Technology And Patient Safety: Evidence From Panel Data. Health Aff 2009, 28(Suppl 2):357-360.

8. Wang SJ, Middleton B, Prosser LA, Bardon CG, Spurr CD, Carchidi PJ, Kittler AF, Goldszer RC, Fairchild DG, Sussman AJ, Kuperman GJ, Bates DW: A cost-benefit analysis of electronic medical records in primary care. Am J Med 2003, 114(Suppl 5):397-403.

9. Rosemann T, Joest K, Körner T, Schaefert R, Heiderhoff M, Szecsenyi J: How can the practice nurse be more involved in the care of the chronically ill? The perspectives of GPs, patients and practice nurses. BMC Fam Pract 2006, 7:14.

10. Wagner $\mathrm{EH}$, Austin BT, Davis C, Hindmarsh M, Schaefer J, Bonomi A: Improving chronic illness care: translating evidence into action. Health Aff (Millwood) 2001, 20(Suppl 6):64-78.

11. Bodenheimer $T$, Wagner EH, Grumbach K: Improving primary care for patients with chronic illness. JAMA 2002, 288(Suppl 14):1775-1779.

12. Bodenheimer $\mathrm{T}$, Wagner $\mathrm{EH}$, Grumbach $\mathrm{K}$ : Improving primary care for patients with chronic illness: the chronic care model, Part 2. JAMA 2002, 288(Suppl 15):1909-1914.

13. Persell SD, Kaiser D, Dolan NC, Andrews B, Levi S, Khandekar J, Gavagan T, Thompson JA, Friesema EM, Baker DW: Changes in performance after implementation of a multifaceted electronic-health-record-based quality improvement system. Med Care 2011, 49(Suppl 2):117-125.

14. Jones SS, Adams JL, Schneider EC, Ringel RS, McGlynn EA: Electronic Health Record Adoption and Quality Improvement in US Hospitals. Am J Manag Care 2010, 16:64-71

15. Hippisley-Cox J, Pringle M, Cater R, Wynn A, Hammersley V, Coupland C, Hapgood R, Horsfield P, Teasdale S, Johnson C: The electronic patient record in primary care-regression or progression? A cross sectional study. BMJ 2003, 326:1439-1443.

16. Ventres $W$, Kooienga $S$, Vuckovic N, Marlin R, Nygren P, Stewart V: Physicians, patients, and the electronic health record: an ethnographic analysis. Ann Fam Med 2006, 4(Suppl 2):124-131.

17. Adams WG, Mann AM, Bauchner H: Use of an Electronic Medical Record Improves the Quality of Urban Pediatric Primary Care. Pediatrics 2003, 111(Suppl 3):626-632.

18. Durieux $P$, Trinquart $L$, Colombet I, Niès J, Walton R, Rajeswaran A, Rège Walther M, Harvey E, Burnand B: Computerized advice on drug dosage to improve prescribing practice. Cochrane Database Syst Rev 2008, Issue 3:Art. No:CD002894

19. Hysong SJ, Sawhney MK, Wilson L, Sittig DF, Esquivel A, Singh S, Singh H: Understanding the management of electronic test result notifications in the outpatient setting. BMC Med Inform Decis Mak 2011, 11:22.

20. Hettiger S: Medicare Electronic Prescribing Incentive Program update. Mich Med 2011, 110(Suppl 5):6-7.

21. Teich JM: Merchia PR, Schmiz JL, Kuperman GJ, Spurr CD, Bates DW: Effects of Computerized Physician Order Entry on Prescribing Practices. Arch Intern Med 2000, 160:2741-2747.

22. Abramson EL, Barrón Y, Quaresimo J, Kaushal R: Electronic prescribing within an electronic health record reduces ambulatory prescribing errors. Jt Comm J Qual Patient Saf 2011, 37(Suppl 10):470-478.

23. Fischer MA, Vogeli C, Stedman M, Ferris T, Brookhart MA, Weissman JS: Effect of Electronic Prescribing With Formulary Decision Support on Medication Use and Cost. Arch Intern Med 2008, 168(Suppl 22):2433-2439.

24. Crosson JC, Etz RS, Wu S, Straus SG, Eisenman D, Bell DS: Meaningful use of electronic prescribing in 5 exemplar primary care practices. Ann Fam Med 2011, 9(Suppl 5):392-397.

25. Grossman JM, Cross DA, Boukus ER, Cohen GR: Transmitting and processing electronic prescriptions: experiences of physician practices and pharmacies. J Am Med Inform Assoc 2012, 19:353-359.

26. Shojania KG, Jennings A, Mayhew A, Ramsay CR, Eccles MP, Grimshaw J: The effects of on-screen, point of care computer reminders on processes and outcomes of care. Cochrane Database Syst Rev 2009, Issue 3:Art.No.: CD001096.

27. O'Connor PJ, Sperl-Hillen JM, Rush WA, Johnson PE, Amundson GH, Asche SE, Ekstrom HL, Gilmer TP: Impact of electronic health record clinical decision support on diabetes care: a randomized trial. Ann Fam Med 2011, 9(Suppl 1):12-21.
28. Birmingham E, Catallozzi M, Findley SE, Vawdrey DK, Kukafka R, Stockwell MS, FluAlert: A qualitative evaluation of providers' desired characteristics and concerns regarding computerized influenza vaccination alerts. Prev Med 2011, 52:274-277.

29. Terschuren $C$, Mensing M, Mekel OCL: Is telemonitoring an option against shortage of physicians in rural regions? Attitude towards telemedical devices in the North Rhine-Westphalian health survey. Germany. BMC Health Services Research 2012, 12:95.

30. Ye J, Rust G, Fry-Johnson Y, Strothers H: E-mail in patient-provider communication: a systematic review. Patient Educ Couns 2010, 80(Suppl 2):266-273.

31. Laurant M, Reeves D, Hermens R, Braspenning J, Grol R, Sibbald B: Substitution of doctors by nurses in primary care. Cochrane Database Syst Rev 2004, Issue 4:Art.No.:CD001271.

32. Bodenheimer T, Laing BY: The Teamlet Model of Primary Care. Ann Fam Med 2007, 5(5):457-461.

33. Peters K, FOlbort R, Campbell S, Mahler C, Miksch A, Baldauf A, Szecsenyi J: Physicians' view of primary care-based case management for patients with heart failure: a qualitative study. Int J Qual Health Care 2009, 21:1-9.

34. Bölter R, Ose D, Götz K, Miksch A, Szecsenyi J, Freund t: Involvement of Doctors' Assistants in Primary Care for Patients with Long-Term Conditions. General Practitioners' (GPs) Perception of Barriers and Opportunities - a Qualitative Study]. Einbeziehung nichtärztlicher Gesundheitsberufe in die Primärversorgung chronisch kranker Patienten Chancen und Barrieren aus Sicht deutscher Hausärzte. Med Klin 2010, 105:7-12.

35. Mahler C, Trieschmann J, Szecsenyi J, Rosemann T: [Motivational aspects of medical staff assistants regarding further education - results of a survey]. Fortbildungsmotivation von Arzthelferinnen - Ergebnisse einer Befragung. Z Allg Med 2007, 83:191-196.

36. Institut für hausärztliche Fortbildung im Deutschen Hausärzteverband e.V: Versorgungsassistentin in der Hausarztpraxis - VERAH ${ }^{\circledR}$. [http://www.verah.de/ a7f7cf2f-df4e-4921-a1ff-2c901a12cde8.html?1252318927244].

37. van den Berg N, Meinke C, Heymann R, Fiss T, Suckert E, Pöller C, Dreier A, Hoffmann W, Rogalski H, Oppermann R, Karopka T: AGnES: supporting general practitioners with qualified medical practice personnel: model project evaluation regarding quality and acceptance. Dtsch Arztebl Int 2009, 106(Suppl 1-2):3-9.

38. Flintrop J, Merten $M$, Gerst T: Delegation of medical service. Deficiency makes many things possible.] Delegation ärztlicher Leistung. Mangel macht vieles möglich. Dtsch Ärzteb/ 2008, 105(Suppl 19):979-981.

39. Creavin ST, Creavin AL, Mallen CD: Do GPs respond to postal questionnaire surveys? A comprehensive review of primary care literature. Fam Pract 2011, 28(4):461-467.

40. Bonevski B, Magin P, Horton G, Foster M, Girgis A: Response rates in GP surveys - trialling two recruitment strategies. Aust Fam Physician 2011, 40(6):427-430

doi:10.1186/1472-6947-12-81

Cite this article as: Urban et al:: Technical support and delegation to practice staff - status quo and (possible) future perspectives for primary health care in Germany. BMC Medical Informatics and Decision Making 2012 12:81.

\section{Submit your next manuscript to BioMed Central and take full advantage of:}

- Convenient online submission

- Thorough peer review

- No space constraints or color figure charges

- Immediate publication on acceptance

- Inclusion in PubMed, CAS, Scopus and Google Scholar

- Research which is freely available for redistribution 